\title{
Review Article \\ Physical Properties of Gas Hydrates: A Review
}

\author{
Jorge F. Gabitto ${ }^{1}$ and Costas Tsouris ${ }^{2}$ \\ ${ }^{1}$ Department of Chemical Engineering, Prairie View A\&M University, Prairie View, TX 77446-0397, USA \\ ${ }^{2}$ Oak Ridge National Laboratory, Georgia Institute of Technology, Oak Ridge, TN 37831-6181, USA
}

Correspondence should be addressed to Costas Tsouris, tsourisc@ornl.gov

Received 6 August 2009; Accepted 23 November 2009

Academic Editor: Jae Lee

Copyright (C) 2010 J. F. Gabitto and C. Tsouris. This is an open access article distributed under the Creative Commons Attribution License, which permits unrestricted use, distribution, and reproduction in any medium, provided the original work is properly cited.

Methane gas hydrates in sediments have been studied by several investigators as a possible future energy resource. Recent hydrate reserves have been estimated at approximately $10^{16} \mathrm{~m}^{3}$ of methane gas worldwide at standard temperature and pressure conditions. In situ dissociation of natural gas hydrate is necessary in order to commercially exploit the resource from the natural-gashydrate-bearing sediment. The presence of gas hydrates in sediments dramatically alters some of the normal physical properties of the sediment. These changes can be detected by field measurements and by down-hole logs. An understanding of the physical properties of hydrate-bearing sediments is necessary for interpretation of geophysical data collected in field settings, borehole, and slope stability analyses; reservoir simulation; and production models. This work reviews information available in literature related to the physical properties of sediments containing gas hydrates. A brief review of the physical properties of bulk gas hydrates is included. Detection methods, morphology, and relevant physical properties of gas-hydrate-bearing sediments are also discussed.

\section{Introduction}

Clathrate hydrates or gas hydrates are solid structures. Water molecules are linked through hydrogen bonding and create cavities (host lattice) that can enclose a large variety of molecules (guests). No chemical bonding takes place between the host water molecules and the enclosed guest molecule. The clathrate hydrate crystal may exist at temperatures below as well as above the normal freezing point of water [1].

Clathrate hydrates of current interest are composed of water and the following molecules: methane, ethane, propane, isobutane, normal butane, nitrogen, carbon dioxide, and hydrogen sulfide. However, other nonpolar components between the sizes of argon $(0.35 \mathrm{~nm})$ and ethylcyclohexane $(0.9 \mathrm{~nm})$ can also form hydrates. Clathrate hydrates, commonly called gas hydrates, form at temperatures close to $273 \mathrm{~K}$ and elevated pressures [2].

The discovery of gas hydrates is credited to Sir Humphrey Davy [3] in 1810. Due to their crystalline, nonflowing nature, hydrates first became of interest to the hydrocarbon industry in 1934, when they were first observed [4] blocking pipelines. Hydrates concentrate hydrocarbons: $1 \mathrm{~m}^{3}$ of hydrates may contain as much as $180 \mathrm{SCM}$ (standard cubic meters) of gas. Makogon [5] indicated that large natural reserves of hydrocarbons exist in hydrated form, both in deep oceans and in the permafrost. Evaluation of these reserves is highly uncertain, yet even the most conservative estimates concur that there is twice as much energy in hydrated form as in all other hydrocarbon sources combined [3].

Water (the host) molecules form the framework containing relatively large cavities as a result of hydrogen bonding; these cavities are occupied by gas (the guest) molecules, whose diameters are less than the size of the cavities. This hydrate structure is thermodynamically stabilized through nonbonded interactions between the encaged gas and the water lattice. Gas hydrates crystallize in three predominant structures: I (sI), II (sII), and $\mathrm{H}(\mathrm{sH})$, depending on the nature and the size of the guest molecule. There is a strong relationship between hydrate crystal structure and such properties as phase equilibria and heat of dissociation [2].

The following properties of sI and sII are determined by the molecular structure. (i) Mechanical properties approximate those of ice, perhaps because hydrates are $85 \mathrm{~mol} \%$ water, yet each volume of hydrate may contain large volumes of the hydrate-forming species at standard temperature and 
pressure conditions (STP). (ii) Phase equilibrium is set by the size ratio of guest molecules within host cages, and threephase (liquid water-hydrate-vapor; Lw-H-V) equilibrium pressure depends exponentially upon temperature. (iii) Heats of formation are set by the hydrogen-bonded crystals and are reasonably constant within a range of guest sizes [2].

Gas hydrate samples have currently been recovered from 19 or more areas worldwide and are believed to occur at about 77 locations including Antartica and Siberia (Kvenvolden and Lorenson [6]). In general, gas hydrates are found in marine shelf sediments and on-shore polar regions beneath the permafrost [7] because in these two types of settings the pressure-temperature conditions are within the hydrate stability field (Lerche and Bagirov [8]).

Offshore hydrate-bearing sediments have generally been found in waters deeper than $300 \mathrm{~m}$; their zone of existence is from the seafloor to a depth of a few hundred meters, depending upon the local thermal gradient. Enormous amounts of methane are believed to be trapped by hydrates, both in the hydrate crystal structure itself and also in sediments beneath hydrate deposits [9].

The physical properties of gas hydrates trapped in sediments are very important in detecting the presence of these compounds, estimating the amount of gas hydrates trapped in the sediments, and developing processes to exploit this resource. Unfortunately, little is known about the physical properties of natural gas hydrate deposits in nature, making their detection by remote geophysical surveys difficult. The presence of gas hydrates in marine sediments dramatically alters some of the normal physical properties of the sediment, which can be detected by field measurements and by downhole logs [7].

The main goal of this work is to review some of the efforts made to determine physical property values for sediments partially, or completely, filled with gas hydrates. In order to achieve this goal, we will review the physical properties of bulk gas hydrates, the morphology of marine sediments, and models used to predict the properties of gas-hydrate-bearing sediments.

\section{Bulk Gas Hydrates}

2.1. Structures of Pure Gas Hydrates. The crystal structures of sI and sII hydrates were first determined in the late 1940s and early 1950s by von Stackelberg and coworkers using $\mathrm{X}$-ray diffraction [3]. This discovery was followed by more extensive X-ray diffraction studies of these hydrate structures in 1965 by McMullan and Jeffrey [10] and by Mak and McMullan [11].

These structures differ in the number and sizes of the cages and in their unit cells (Table 1). The type of crystal structure that forms depends on the size of the guest molecule; for example, $\mathrm{CH}_{4}$ and $\mathrm{C}_{2} \mathrm{H}_{6}$ both form sI hydrate, $\mathrm{C}_{3} \mathrm{H}_{8}$ forms sII hydrate, while larger guest molecules such as cyclopentane in the presence of methane form $\mathrm{sH}$ hydrate [11]. Both sI and sII hydrates have cubic crystal structures, while $\mathrm{sH}$ hydrate has a hexagonal crystal structure. All these hydrate structures are composed of two or more types of water cages packed within the crystal lattice. The water cages are described by the general notation $X^{n}$, where $X=$ the number of sides of a cage face, and $n=$ the number of cage faces having these $X$ sides. It is not necessary for all cages to be occupied; for example, methane hydrate can be prepared with just $90 \%$ of the small cages occupied by methane. The sI and sII hydrate structures are of particular importance in the gas industry because they encage small gas molecules that are found in natural gas. The sI hydrate structure contains two different types of cavities: a pentagonal dodecahedral cavity (12-hedra), denoted $5^{12}$ (comprising 12 pentagons), and a larger tetracaidecahedral cavity (14-hedra), denoted $5^{12} 6^{2}$ (comprising 12 pentagons and 2 hexagons). The packing in sI hydrate can be described as $5^{12}$ cavities sharing vertices, with no direct face sharing occurring between these 12-hedra. The vertices of the 14-hedra are arranged in columns in which 12-hedra occupy the space between each pair of 14-hedra. The unit cell of sII hydrate also contains two different types of cavities: a small $5^{12}$ cavity and a hexacaidecahedral cavity (16-hedra), denoted $5^{12} 6^{4}$ (comprising 12 pentagons and 4 hexagons), which is slightly larger that the $5^{12} 6^{2}$ cavity found in sI hydrate. The packing in sII hydrate can be described as $5^{12}$ cavities sharing faces in $3 \mathrm{D}$, with the void spaces being occupied by the 16-hedra (Koh [12]).

The hydrate structure $\mathrm{sH}$, named for the hexagonal framework, was discovered [13] and shown by Ripmeester et al. [14] to have cavities large enough to contain molecules the size of common components of naphtha and gasoline. Physical properties, phase equilibrium data, and models have been advanced [15-18], and one instance [19] of in situ $\mathrm{sH}$ has been found in the Gulf of Mexico [12].

In 2001 a new hydrate structure, sT hydrate, has been discovered [20] in which all three types of large cages $\left(5^{12} 6^{3}\right.$, $5^{12} 6^{2}$, and $4^{1} 5^{10} 6^{3}$ ) in the structure are occupied by dimethyl ether guest molecules. The crystal structure in sT hydrate is trigonal [12]. In addition to the hydrate structures discussed above, two new structures have been discovered [21, 22] at higher pressures. Recently, Yang et al. (2009) [23] observed and characterized using X-ray diffraction and NMR a true clathrate hydrate containing only Xe atoms as guests. This form was produced from an initial pressurization of sI Xe hydrate followed by a temperature quench recovery. It is likely that more hydrate structure types will be discovered in the future. Table 1 provides a hydrate structure summary for the three most common hydrate unit crystals (sI, sII, and $\mathrm{sH})$.

2.2. Physical Properties of Bulk Gas Hydrates. Sloan [2] provided a review of time-independent physical/chemical properties as they relate to crystal structures. According to Sloan, if all the cages of each structure are filled, all three structures (sI, sII, and $\mathrm{sH}$ ) of hydrates have the property of being approximately $85 \%$ (mol) water and $15 \%$ gas. The fact that the water content is so high suggests that the mechanical properties of the three hydrate structures should be similar to those of ice. This conclusion is true to a first approximation, as shown in Table 2, with the exception of thermal conductivity and thermal expansivity [24, 25]. Sloan [2] proposed that the guest/cavity size ratio provides an adequate basis to understand the physical properties of bulk 
TABLE 1: Geometrical parameters of the main hydrate crystal structures (data taken from $[2,3,12])$.

\begin{tabular}{|c|c|c|c|c|c|c|c|}
\hline \multirow[b]{2}{*}{ Cavity } & \multicolumn{2}{|c|}{ Structure I } & \multicolumn{2}{|c|}{ Structure II } & \multicolumn{3}{|c|}{ Structure H } \\
\hline & small & large & small & large & small & medium & large \\
\hline Description & $5^{12}$ & $5^{12} 6^{2}$ & $5^{12}$ & $5^{12} 6^{4}$ & $5^{12}$ & $4^{3} 5^{6} 6^{3}$ & $5^{12} 6^{8}$ \\
\hline Cavities/unit cell & 2 & 6 & 16 & 8 & 3 & 2 & 1 \\
\hline Average cavity radius, $\mathrm{nm}$ & 0.395 & 0.433 & 0.391 & 0.473 & 0.391 & 0.406 & 0.571 \\
\hline Coordination number & 20 & 24 & 20 & 28 & 20 & 20 & 36 \\
\hline Water moleculesper unit cell & \multicolumn{2}{|c|}{46} & \multicolumn{2}{|c|}{136} & \multicolumn{3}{|c|}{34} \\
\hline Lattice type & \multicolumn{2}{|c|}{ Cubic } & \multicolumn{2}{|c|}{ Face-centered cubic } & \multicolumn{3}{|c|}{ Hexagonal } \\
\hline Unit cell parameters, nm & \multicolumn{2}{|c|}{$a=1.2$} & \multicolumn{2}{|c|}{$a=1.7$} & \multicolumn{3}{|c|}{$a=1.21, c=1.01$} \\
\hline Density, $\mathrm{kg} \mathrm{m}^{-3}$ & \multicolumn{2}{|c|}{912} & \multicolumn{2}{|c|}{940} & \multicolumn{3}{|c|}{1952} \\
\hline
\end{tabular}

TABLE 2: Comparison of properties of ice, sI, and sII hydrate crystal structures (data taken from $[2,3]$ ).

\begin{tabular}{|c|c|c|c|}
\hline Property & Ice $\left(I_{h}\right)$ & Structure I & Structure II \\
\hline Water molecules number & 4 & 46 & 136 \\
\hline Lattice parameters at $273 \mathrm{~K}, \mathrm{~nm}$ & $a=0.452, c=0.736$ & 1.20 & 1.73 \\
\hline Dielectric constant at $273 \mathrm{~K}$ & 94 & $\sim 58$ & 58 \\
\hline Water diffusion correlation time, $\mu \mathrm{s}$ & 220 & 240 & 25 \\
\hline Water diffusion activation energy, $\mathrm{kJ} / \mathrm{m}$ & 58.1 & 50 & 50 \\
\hline Isothermal Young's modulus at $268 \mathrm{~K}, 10^{9} \mathrm{~Pa}$ & 9.5 & 8.4 (est.) & 8.2 (est.) \\
\hline Poisson's ratio & 0.33 & $\sim 0.33$ & $\sim 0.33$ \\
\hline Bulk modulus (272 K) & 8.8 & 5.6 & $N A$ \\
\hline Shear modulus ( $272 \mathrm{~K})$ & 3.9 & 2.4 & $N A$ \\
\hline Compressional velocity $\left(V_{p}\right), \mathrm{m} / \mathrm{s}$ & 3870.1 & 3778.0 & 3821.8 \\
\hline Shear velocity $\left(V_{s}\right), \mathrm{m} / \mathrm{s}$ & 1949 & 1963.6 & 2001.1 \\
\hline Velocity ratio (comp./shear) & 1.99 & 1.92 & 1.91 \\
\hline Linear thermal expn., at $200 \mathrm{~K}, \mathrm{~K}^{-1}$ & $5610^{-6}$ & $7710^{-6}$ & $5210^{-6}$ \\
\hline Adiab. bulk compress. $(273 \mathrm{~K}), 10^{-11} \mathrm{~Pa}$ & 12 & 14 (est.) & 14 (est.) \\
\hline Heat Capacity, $\mathrm{J} \mathrm{kg}^{-1} \mathrm{~K}-{ }^{1}$ & 3800 & 3300 & 3600 \\
\hline Thermal conductivity $(263 \mathrm{~K}), \mathrm{W} \mathrm{m} \mathrm{m}^{-1} \mathrm{~K}^{-1}$ & 2.23 & $0.49 \pm 0.02$ & $0.51 \pm 0.02$ \\
\hline Refractive index, $638 \mathrm{~nm},-3^{\circ} \mathrm{C}$ & 1.3082 & 1.3460 & 1.350 \\
\hline Density, $\mathrm{kg} \mathrm{m}^{-3}$ & 916 & 912 & 940 \\
\hline
\end{tabular}

gas hydrates. The concept of "a ball fitting within a ball" was proposed as a first approximation. Sloan enunciated the following five points regarding the guest-cavity size ratio for hydrates formed from a single guest component in sI or sII.

(1) The size of the stabilizing guest molecules ranges between 0.35 and $0.75 \mathrm{~nm}$. Molecules smaller than $0.35 \mathrm{~nm}$ will not stabilize the sI structure, and molecules larger than $0.75 \mathrm{~nm}$, will not stabilize the sII structure.

(2) Some molecules are too large to fit the smaller cavities of each structure.

(3) Other molecules such as $\mathrm{CH}_{4}$ and $\mathrm{N}_{2}$ are small enough to enter both the small and large cavities when hydrate is formed from these single components.

(4) The larger molecules of a gas mixture usually determine the structure that is formed. The larger components enter into large cavities only, while smaller components enter both cavities.

(5) Molecules which are very close to the lines separating the cavity sizes change the stoichiometry, due to their inability to fit comfortably within the cavity.

Sloan [2] noted that a size ratio (guest molecule size divided by the cavity size) of approximately 0.9 is necessary to achieve stability of a hydrate structure. When the size ratio exceeds unity, the molecule will not fit within the cavity and the structure will not form. When the ratio is less than 0.9, the molecule cannot lend significant stability to the cavity [2].

Phase equilibrium is set by the size ratio of guest molecules within host cages, and the three-phase (Lw$\mathrm{H}-\mathrm{V}$ ) equilibrium pressure depends exponentially upon temperature. Heats of formation are set by the hydrogenbonded crystals and are reasonably constant within a range of guest sizes [2]. 
Thermal conductivities of a few gas hydrates have been published by Cook and Leaist [26] (1981), Ross et al. [27] (1978), Stoll and Bryan [28] (1979), and Ashworth et al. [29] (1985). These values are much smaller than those of ice (Ih) both at and well bellow the freezing point (Tse and White [30], 1988).

In contrast with most well-defined crystalline structures, in which the thermal conductivity falls with increasing temperature following a $T^{-1}$ dependence (for $T>100 \mathrm{~K}$ ), the thermal conductivity of clathrate hydrates increases slightly with increasing temperature (Tse and White [30]). The thermal conductivity of clathrate hydrates is five times lower than that of ice near the melting point, and even lower (by a factor $>20$ ) at lower temperatures. The temperature dependence of thermal conductivity in clathrate hydrates is characteristic of an amorphous material (Tse and White [30]).

Based on the low-temperature thermal conductivity of tetrahydrofuran (THF) clathrate hydrates, Anderson and Suga [31] suggested that, despite the well-defined crystalline structures, clathrate hydrates show glassy behavior attributable to low-frequency guest vibrations, causing the clathrate hydrates to be thermal glasses.

From measurements of thermal conductivity at relatively high temperatures, it appears that the unusual thermal conductivity is insensitive to the crystal structure and dependent on the host. As a result of all the measurements of thermal conductivity of clathrate hydrates, it can be concluded that these compounds are very poor thermal conductors. Furthermore, the large difference in the thermal conductivity of pure ice and clathrate hydrates provides a criterion for locating regions of shelf ice which contain potential energy reserves in the form of methane or similar gases. Thermal conductivity is also a vital parameter required for modeling the recovery of natural gas from hydrates; knowledge of the variation of the thermal conductivity with pressure and temperature is required for successful methane hydrates exploitation [32].

The heat of dissociation $\left(\Delta H_{d}\right)$ is defined as the enthalpy change to dissociate the hydrate phase to a vapor and aqueous liquid, with values given at temperatures just above the ice point. For sI and sII, to a fair engineering approximation of $10 \%$, it has been shown [3] that $\Delta H_{d}$ is a function of the number of crystal hydrogen bonds (loosely taken as hydration number). However, the value of $\Delta H_{d}$ is relatively constant for molecules which occupy the same cavity, within a wide range of component sizes. Enthalpies of dissociation may be determined via the univariant slopes of phase equilibrium lines $(\ln P$ versus $1 / T)$ in the previous paragraphs, using the Clausius-Clapeyron relation $\left[\left(\Delta H_{d}\right)=-z R d(\ln P) / d(1 / T)\right]($ Sloan $[2])$.

\section{Gas-Hydrate-Bearing Sediments}

3.1. Seismic Detection Methods. The presence of gas hydrates in offshore continental margins has been inferred mainly from seismic processing techniques. Seismic image processing visualizes the subsurface structure by means of reflected acoustic signals. The seafloor signal is marked by a white/black reflection, which means that the subsurface volume is harder than the volume above. In acoustic terms, the acoustic impedance (the product of medium density and speed of sound) below the seafloor in the sediment is higher than the impedance of the water column. In contrast, the bottom-simulating reflector (BSR) is marked by a black/white reflection indicating possibly high hydrate impedance above gas-filled sediments with low impedance. As the resolution of the seismic image is limited by the seismic source bandwidth and as the physical parameters describing the seismic subsurface response are frequency dependent, multiple surveys with different acquisition parameters are needed to obtain a more complete knowledge of the sediment parameters [33].

Seismic measuring arrays are composed of a sound source, such as air guns (usually a dozen or more of them), and moving or stationary receivers; the reflected sound waves provide a 2D image of a slice through the earth's surface. The sound waves travel through the water column and back as compression or $P$ waves, representing the vertical motion through the different materials [34]. There is also interest in other seismic methods, such as the use of shear or $S$ waves. Shear waves have different vector components of horizontal movement and are converted from compression waves passing through gas hydrate zones. Because compression and shear waves deform materials differently, some researchers are using these differences to learn more about the amount and distribution of gas hydrate [35].

Locating likely areas of gas hydrates using remote seismic sensing is relatively straightforward in many parts of the world where the BSR is readily evident. Because the BSR follows a thermobaric surface rather than a structural or stratigraphic interface, it is normally observed to crosscut other reflectors. The BSR usually marks the base of a gas hydrate layer below which there is free gas. However, hydrate samples have been taken in areas where no BSR was found. One reason is that because the BSR represents the base of stable hydrates and is the seismic image of the interface between solid hydrate and free gas, where no free gas is present, there is no BSR even though hydrates may well be present [36]. Furthermore, it is difficult to quantify the volume fraction of hydrates in the shallow section from seismic data alone. Gas hydrates are electrically more resistive than the host sediments; therefore, they will have an electromagnetic signature that increases with hydrate volume fraction. Indeed, well logs indicate increased resistivity in zones of gas hydrate, although this effect is sometimes modest. Marine electromagnetic (EM) methods have long been proposed as an effective way to map and characterize gas hydrates, notably by Nigel Edwards at the University of Toronto. The Hydrate Ridge work represented the first attempt to apply the EM methods recently developed for oil field characterization to the hydrate question. The data are promising, but this survey was a pilot study with less than 4 days of ship time available on station. Furthermore, the physical characteristics of in situ hydrate vary considerably, and Hydrate Ridge, while a good test of the method because of the extensive seismic and drilling data sets available, may not be characteristic of hydrates in 
more commercially relevant areas, such as the Gulf of Mexico [37].

3.2. Hydrate Morphology in Sediments. Gas hydrate morphology describes the relationship between gas hydrates and the surrounding marine sediments. The morphology of gas hydrates determines the basic physical properties of the sediment-hydrate matrix. Many remote techniques for gas hydrate detection and quantification are highly dependent on the hydrate morphology. Little attention has been paid to the hydrate morphology until now because previous methods of hydrate collection preserved only the grossest morphologies (e.g., lumps and nodules of hydrate [38]). However, recent advances in pressure coring and pressure core analysis have allowed collection of samples with intact gas-hydrate-sediment morphologies, which show that gas hydrates often take on complex forms which will require new approaches to both conceptualizing and modeling gas hydrate dynamics. The recent use of borehole pressure coring tools has allowed marine gas-hydrate-bearing sediments to be recovered containing centimeter to sub-millimeter gas hydrate structures preserved in their in situ condition [38].

Clear knowledge of detailed gas hydrate morphology will provide critical data to help determine the mechanisms of gas hydrate deposit formation and to model the kinetics of deposit dissociation from both natural and artificial causes. The morphology also has a significant effect on sedimentary physical properties, from seismic velocities on a large scale to borehole electrical resistivity on a smaller scale, and will thus impact the amount of gas hydrate saturation estimated from geophysical data [38].

Malone (1985) [39] described four possible hydrate morphologies using the terminology disseminated, nodular, vein, and massive. Disseminated hydrate occurs within the pore space of the sediment, while the other three forms occur where the sediment is disturbed either by regional tectonic stresses or through the stress resulting from hydrate crystal growth. For instance, Cook and Goldberg (2007) [40] found hydrate-bearing fractures to be oriented with respect to regional tectonic stresses offshore India. However, some researchers have not found this classification useful to further our understanding of sediment-hydrate interactions [41].

Theoretical work on hydrate formation (Clennell et al. [42]; Henry et al. [43]) explored the influence of capillary pressure and thermodynamics on hydrate growth and provided some real physical constraints to hydrate morphology. It was concluded that hydrate growth in fine-grained mud would be unlikely, and that coarser-grained sediments, exhibiting larger pores, would act as more likely hosts. Theoretical considerations suggested that hydrate morphology is controlled by the nature of the sediment host as much as by the supply of the necessary chemical components and environmental conditions (water, gas, nucleation sites, temperature, and pressure). This theoretical work is also supported by experimental studies (Kleinberg et al. [44], 2003; Camps [45], 2007) and by observations (e.g., Riedel et al. $[46], 2006)$ where disseminated hydrate is limited to coarsergrained sediments and the other forms tend to occur in finergrained sediments where the sediment fabric is disturbed.
Similar observations were found through investigations of hydrate dissociation conditions (Anderson et al. [47], 2003; Llamedo et al. [48], 2004). These observations revealed that dissociation is more readily achieved within small pores as compared to large pores, suggesting the possibility of hydrate breakdown in small pores rather than in adjacent large pores [41].

Significant advances in characterizing the relationship between sediments and hydrates have been recently achieved [38]. For instance, Tinivella et al. [49] have quantified the concentrations of gas hydrate in pore space by traveltime inversion modeling of the acoustic properties of these sediments. Such analysis has allowed the identification of free gas distribution in pore spaces, likely patterns of fluid migration, the physical properties of sediments, and the consequent origin of the BSR offshore the Antarctic Peninsula [41].

At other sites, hydrate volumes have often been estimated using electrical or acoustic measurements and relating these parameters (electrical resistivity and acoustic velocity) to the hydrate concentration or saturation in the pore space. Such studies usually assume the hydrate is disseminated in the pore space and that the sediment remains wet, comparable to oil-bearing reservoirs. Ecker et al. [50] and Dvorkin et al. [51] demonstrate that knowledge of the interaction between hydrate and sediment grains is crucial in achieving well-constrained volume estimates of hydrate. It is also recognized that the use of Archie's equations [52] assumes the hydrate does not completely block off the pore space at low saturations, treating hydrate as a hydrocarbon fluid [41].

The estimation of the hydrate content using downhole electrical measurements based on Archie's law requires the knowledge of the saturation exponent. The saturation exponent is an empirical parameter that includes influences from the internal rock structure such as pore shape, size, connectivity of the pore network, and the distribution of the conducting phase. Spangenberg [53] used different models, which account for different morphological forms of gas hydrates, to study the influence of gas hydrate content on the electrical properties of the hydrate-bearing sediment. The author concluded that for all studied forms of hydrate occurrence, disseminated in the pore space, nodular, and layered, the saturation exponent depends on the sediment properties and on saturation itself. The growth of gas hydrate nodules, lenses, and layers is a process that is assumed to result in the displacement and compaction of the surrounding sediment. Because of this change of sediment properties during hydrate generation, the saturation exponent for these forms of hydrate occurrence depends strongly on the relationship between porosity and formation resistivity factor, expressed in the form of Archie's cementation exponent. For the case that hydrate occurs disseminated in the pore space and the assumption that capillary effects are important for hydrate generation, the saturation exponent depends on grain size and grain size sorting. Spangenberg [53] reported that, for the parameters used in his model calculations, the saturation exponent varies between 0.5 and 4 .

Holland et al. [38] proposed that gas hydrate morphologies are found in two basic types: pore filling and grain 
displacing. Pore-filling morphologies of gas hydrate replace pore fluid between grains of sediment; this gas hydrate may or may not cement grains together. Grain-displacing gas hydrate does not occupy the pore volume between grains but, instead, forces grains apart, forming veins, layers, and lenses of pure gas hydrate. Grain-displacing hydrate may cover a vast range of sizes, from thin veins of possibly only a few microns thick to nodules of tens of centimeters or even meters in diameter. Holland et al. suggested that "grain displacing" and "pore filling" are not equivalent to the terms "massive" and "disseminated" but that these terms apply to cores which have already undergone gas hydrate dissociation, where massive gas hydrate is still visible, and disseminated gas hydrate is invisible to the naked eye, and may have already been completely dissociated [38].

Tohidi et al. [54] conducted visualization experiments using two-dimensional transparent glass micro-models and reported that hydrates can form from either free or dissolved gas. They also reported that hydrates usually form within the center of pore spaces, with a thin film of water covering the grains, rather than nucleating on grain surfaces.

Kingston et al. [55] used a specially constructed laboratory porous medium, gas hydrate resonant column (GHRC), to explore different methods of hydrate synthesis and measure the properties of the resulting sediments. The authors studied different water saturation conditions of the porous medium. In low water saturation tests, or conditions where the environment is gas saturated, the hydrate will grow on the water location; therefore, the water saturation becomes the restricting factor on hydrate content. In partially saturated sands, water tends to collect at grain contacts and coat individual sand grains. Hydrate will therefore preferentially grow at grain contacts, effectively cementing the rock grains. As hydrate content is increased, it begins to fill the pores, but the increased stiffening is likely to be produced by the increased quantity of "cement" at grain contacts. In fully water saturated tests, the morphology of the hydrate appears to be different. Under these conditions, the presence of gas bubbles suspended in water-filled pores was reported before hydrate formation. In this case, hydrate will form at the gas/water interface (i.e., around gas bubbles). The hydrate has now become a pore-filling component, and only large amounts of hydrate in the pore space will have a significant effect on the physical properties [55].

The production of natural gas from oceanic and permafrost sediments is currently being developed using such methods as depressurization, thermal stimulation, and injection of hydrate inhibitors (Moridis et al. [56], 2004). It is important to understand the physical properties of sediments in investigations of structural properties, such as permeability, hydrate saturation, and sediment porosity, since these properties are essential to the development of natural gas production. The porosity is particularly important for material flow in sediment due to the relationship between porosity and permeability (Koponen et al. [57]; Singh and Mohanty [58], Bernabè et al. [59]; Arns et al. [60], among others). Hydrate saturation is required to estimate the physical properties of sediments.
Different experimental techniques have been used to determine these structural parameters. Jin et al. [61] used microfocus X-ray computed tomography (CT) to study the structure of natural gas sediments with and without gas hydrates. The authors applied a newly developed highpressure vessel for the microfocus X-ray CT system to observe the sediments at a temperature above $273 \mathrm{~K}$ and under high-pressure conditions. Jin et al. [62] used twodimensional CT images to measure the spatial distribution of the free-gas, sand particles, liquid water, and solid hydrate phases.

Jin et al. [62] assessed the permeability of sediments via the correlation between the absolute permeability and the pore network in sediments. The continuous pore channel, which allows gas and water flow, was analyzed from the three-dimensional sediment images using a microfocus $\mathrm{X}$ ray computed-tomography system. Their results showed that the proportion of the horizontal-continuous pore channel in terms of direction is a dominant factor in determining the absolute permeability. The absolute permeability of the sediment correlated well with the distribution of the continuous pore channel.

Minagawa et al. [63] used proton nuclear magnetic resonance (NMR) measurements combined with a permeability measurement system to characterize methanehydrate-bearing sediment based on pore-size distribution and permeability. They compared the effective permeability of sediments with different effective porosities, which had been measured by water flow based on Darcy's law, with the permeability calculated by NMR spectra based on the SDR (Schlumberger-Doll Research) model. The permeability calculated by both methods was similar, with a difference between them of less than a factor of 2. Minagawa et al. [63] used their results to describe the relation between pore-size distribution, porosity, and effective permeability.

The presence of pore-scale phenomena, however, could introduce additional complexities. In particular, the effect of pore space geometry; pore-network topology and heterogeneity; and pore space accessibility on gas-phase mobility can influence, among other issues, the ability to economically produce methane gas. To further emphasize the importance of porous sediments, consider that typical pore values found in oceanic sediments are very low. For example, Yang and Alpin [64] reported for mudstones obtained from the Norwegian margin mean pore-throat sizes in the range 8$452 \mathrm{~nm}$ and pore-throat size standard deviation in the range 9-1425 nm. However, hydrate occurrence, in addition to fine-grained sediments, has also been reported in coarser oceanic sediments. A more detailed discussion of this issue is given by Tsimpanogiannis and Lichtner [65], who also considered larger pore values corresponding to onshore sediments under the permafrost as well.

\subsection{Physical Properties of Gas-Hydrate-Bearing Sediments.} The presence of gas hydrates in marine sediments dramatically alters some of the normal physical properties of the sediment, which can be detected by field measurements and by down-hole logs [3]. An understanding of the physical properties of hydrate-bearing sediments is necessary for 
interpretation of geophysical data collected in field settings, borehole, and slope stability analyses; reservoir simulation; and production models.

The physical properties of bulk hydrates are remarkably close to those of pure ice: the compression and shear $(P$ and $S$ ) wave velocities in methane hydrate may reach 3600 and $1900 \mathrm{~m} / \mathrm{s}$, respectively, while its density is $0.912 \mathrm{~g} / \mathrm{cc}$. The corresponding values for ice are 3890 and $1970 \mathrm{~m} / \mathrm{s}$ and $0.916 \mathrm{~g} / \mathrm{cc}$, respectively. As a result, the properties of sediments containing hydrate in the pore space are similar to sediments containing normal ice. However, these sediments are much more rigid than sediments filled solely by water, and unlike ice, methane hydrate can be ignited. A unit volume of hydrate releases about 160 unit volumes of methane (under normal conditions). Also, unlike ice, hydrate can exist at temperatures above $32^{\circ} \mathrm{F}\left(0^{\circ} \mathrm{C}\right)$, but it requires high pore pressure to form and remain stable [66].

Hydrates normally exclude the salt in the pore fluid from which it forms, and thus they have high electric resistivity just as ice and sediments containing hydrates have a higher resistivity compared to sediments without gas hydrates (Judge [67]). The unconsolidated sediments in the upper several hundred meters of the marine sediment section (50\% porosity) normally have a very low resistivity of about $1 \mathrm{ohm}-\mathrm{m}$. For $15-20 \%$ hydrate saturation in the pore space $(7-10 \%$ of sediment), the resistivity increases by about a factor of 2. The most readily observable change in sediment physical properties resulting from the formation of gas hydrates is an increase in seismic velocity. Laboratory-measured seismic velocities for porous media at the maximum hydrate saturation vary from 2700 to $6000 \mathrm{~m} / \mathrm{s}$, depending on the type of sediment and the method of preparation (Stoll et al. [68]; Stoll [69]; Pearson et al. [70]), compared to about $3600 \mathrm{~m} / \mathrm{s}$ in pure methane hydrate [71]. These laboratory determinations are for sediments of much lower porosity and higher velocity than most continental margin sediments near the seafloor. Sediments containing substantial hydrates have enhanced velocities. For example, a hydrate saturation of $10-20 \%$ of pore space in unconsolidated sediment $(50 \%$ porosity at depths of a few hundred meters) has a velocity of $1900-2100 \mathrm{~m} / \mathrm{s}$, compared to no-hydrate velocities of 1600 $1700 \mathrm{~m} / \mathrm{s}$. In general, if hydrates occupy $15 \%$ of pore space, a $15-20 \%$ increase in sediment seismic velocity is expected. This increase can be detected in interval velocities from highquality multichannel seismic data and in well-calibrated down-hole sonic logs. A small quantity, 1-2\%, of free gas in the sediment pore space beneath the BSR will significantly reduce the sediment velocity, while a further increase in gas concentration makes little change (Murphy [72]). The effect of free gas on sediment velocity is highly dependent on water depth primarily because gas density and compressibility are very sensitive to pressure and temperature [36].

Numerous publications report on laboratory measurements of the geophysical and geotechnical properties of hydrate-bearing sediments, but many fundamental challenges remain in using this information to interpret borehole logs or other field data obtained in hydrate zones. The difficulty of maintaining hydrate-bearing sediments within the hydrate stability field has led some researchers to construct specialized devices for their experiments that can be used to reproduce results in other laboratories under exactly the same set of experimental conditions. Santamarina et al. [73] undertook an exhaustive series of laboratory measurements to determine the mechanical, thermal, electri$\mathrm{cal}$, and electromagnetic properties of hydrate-bearing soils using standardized geotechnical devices and test protocols. They conducted experiments on soils with a range of grain sizes subject to an effective stress of up to $2 \mathrm{MPa}$ and with well-controlled saturations of synthetic hydrate [74].

Stoll and Bryan [28] carried out an experimental study to determine the thermal conductivity and acoustic wave velocity in hydrates and sediments containing hydrate. The most significant result of their studies was that the formation of hydrate decreased the thermal conductivity in sediments. This behavior is contrary to what might be expected when compared with the behavior of frozen sediments. Also, based on measurements of acoustic wave velocity, this research confirmed that both pure water and water-bearing sediment are converted to a stiff elastic mass by the formation of a sufficient amount of hydrate. Stoll and Bryan concluded that this finding served as the basis for using the sharp acoustic impedance contrast at the boundary of a hydrate-containing sediment to locate hydrate deposits [28].

Pearson et al. [71] predicted the physical properties of hydrate-containing sediments in order to include their effects on production models and to develop geophysical exploration and reservoir characterization techniques. The authors used empirical relationships between ice composition and seismic velocity, electrical resistivity, density, and heat capacity developed for frozen soils to estimate the physical properties of hydrate deposits. They proposed that the resistivity of laboratory permafrost samples follows a variation of Archie's equation [52]:

$$
\frac{\rho_{f}}{\rho_{t}}=C^{-T} S_{w}^{1-n}
$$

where $\rho_{f}$ and $\rho_{t}$ are the thawed and frozen resistivities of the sample, $T$ is temperature, $S_{w}$ is the unfrozen water content, and $n$ and $C$ are empirical constants. The parameters $C$ and $n$ were calculated for a variety of lithologic types.

Pearson et al. [71] also reported that the compressional wave velocities of partially frozen sediments $\left(V_{p}\right)$ are related to the velocities of the matrix $\left(V_{m}\right)$, the liquid $\left(V_{L}\right)$, and solid $\left(V_{s}\right)$ phases present in the pores by the well-known threephase rule:

$$
\frac{1}{V_{p}}=\left[\varepsilon \frac{S_{w}}{V_{L}}\right]+\left[\varepsilon \frac{\left(1-S_{w}\right)}{V_{s}}+\frac{(1-\varepsilon)}{V_{m}}\right],
$$

where $\varepsilon$ is the porosity.

Pearson et al. proposed that the resistivities and seismic velocities are both functions of the unfrozen water content; however, it was found that resistivities are more sensitive to changes in $S_{w}$ and can vary by as much as three orders of magnitude, which allows the use of electrical resistivity measurements to estimate the amount of hydrate in place. Pearson et al. [71] estimated the unfrozen water content, assuming that the dissolved salt in the pore water 
concentrates as a brine phase as the hydrate forms. Using this technique, they estimated the brine content as a function of depth, assuming a wide range of temperature gradient and pore water salinity values. They also reported that the presence of hydrates tends to lower the heat capacities and densities of sediments, even though these effects are comparatively small.

Pearson et al. [70] reported laboratory acoustic velocity and electrical resistivity measurements on Berea Sandstone and Austin Chalk samples saturated with a stoichiometric mixture of tetrahydrofuran (THF) and water. THF solutions were selected because they form hydrates similar to natural gas hydrates at atmospheric pressures. The authors reported that hydrate formation in both the chalk and sandstone samples increased the acoustic $P$-wave velocities by more than $80 \%$ when hydrates formed in the pore space; however, the velocities soon became constant, and further lowering the temperature did not appreciably increase the velocity. In contrast, the electrical resistivity increased nearly two orders of magnitude upon hydrate formation and continued to increase slowly as the temperature was decreased. The dielectric loss showed a linear decrease with frequency suggesting that ionic conduction through a brine phase dominates at all frequencies, even when the pores are nearly filled with hydrate. The authors also reported that resistivity values were a strong function of the dissolved salt content of the pore water. Pore water salinity also influenced the sonic velocity, but this effect was much smaller.

Winters et al. [75] measured a wide range of acoustic $P$ wave velocities $\left(V_{p}\right)$ in coarse-grained sediments for different pore space occupants. The measured $V_{p}$ values ranged from less than $1000 \mathrm{~m} / \mathrm{s}$ for gas-charged sediments to 1770 $1940 \mathrm{~m} / \mathrm{s}$ for water-saturated sediments, $2910-4000 \mathrm{~m} / \mathrm{s}$ for sediments with varying degrees of hydrate saturation, and $3880-4330 \mathrm{~m} / \mathrm{s}$ for frozen sediment. $V_{p}$ values measured in fine-grained sediments containing gas hydrate were substantially lower $(1970 \mathrm{~m} / \mathrm{s})$. The presence of gas hydrate and other solid pore-filling material, such as ice, increased the sediment shear strength. The magnitude of that increase is related to the amount of hydrate in the pore space and cementation characteristics between the hydrate and sediment grains. Winters et al. found that, for consolidation stresses associated with the upper several hundred meters of sub-bottom depth, pore pressures decreased during shear in coarse-grained sediment containing gas hydrate, whereas pore pressure in fine-grained sediment typically increased during shear. The presence of free gas in pore spaces damped pore pressure response during shear and reduced the strengthening effect of gas hydrate in sands [75].

The research group led by Santamarina collected experimental data to conduct a comprehensive analysis of the values of geophysical and geotechnical properties as a function of hydrate saturation, soil characteristics, and other parameters. Measurements of seismic velocities, electrical conductivity and permittivity, large strain deformation and strength, and thermal conductivity were emphasized in these experiments (Fernandez and Santamarina [76]; Santamarina et al. [74]; Yun et al. [77]; Santamarina et al. [73]).
Santamarina et al. [73] used their data set to identify the systematic effects of sediment characteristics, hydrate concentration, and state of stress, developing mathematical relations for the most relevant material parameters. They reported that, under low strain conditions, the shear wave velocity in hydrate-bearing sediments is stress dependent at low hydrate concentrations but becomes hydrate controlled at high hydrate concentrations. The $P$-wave velocity $\left(V_{p}\right)$ in hydrate-bearing sediments can be computed from the shear wave velocity of the hydrate-bearing sediment $\left(V_{\mathrm{hbs}}\right)$ and the volume fraction and bulk stiffness $\left(B_{i}\right)$ of the component phases. Following a Biot-Gassmann-type formulation for low skeletal stiffness $\left(B_{\mathrm{sk}} / B_{w} \ll 1\right)$, the following relationship can be used (Santamarina et al. [78]):

$$
\begin{aligned}
V_{p}^{2}= & V_{\mathrm{hbs}}^{2}\left(\frac{1-v_{\mathrm{sk}}}{1-2 v_{\mathrm{sk}}}+\frac{4}{3}\right) \\
& +\frac{1}{\rho_{\text {mix }}}\left(\frac{1-\varepsilon}{B_{\text {mix }}}+\varepsilon\left(\frac{S_{h}}{B_{h}}+\frac{1-S_{h}}{B_{w}}\right)\right)^{-1} .
\end{aligned}
$$

The researchers noted that the small strain Poisson's ratio for the skeleton $v_{\mathrm{sk}}$ is typically $0.1 \pm 0.05$. The shear wave velocity in hydrate-bearing sediments $\left(V_{\mathrm{hbs}}\right)$ is stress dependent at low hydrate concentrations but becomes hydrate controlled at high hydrate concentrations. Following these data-based observations, and adopting the form of theoretical expressions for cemented soils (Fernandez and Santamarina [76]), Santamarina et al. [78] fit the data using the following relationship:

$$
V_{\mathrm{hbs}}=\sqrt{\left(\frac{V_{h} S_{h}{ }^{2}}{\varepsilon}\right)^{2} \theta+\left[\alpha\left(\frac{\sigma_{\amalg}^{\prime}+\sigma_{\perp}^{\prime}}{2 \mathrm{kPa}}\right)^{\beta}\right]^{2}} .
$$

Here, $\sigma_{\perp}^{\prime}$ and $\sigma_{\amalg}^{\prime}$ are the effective stresses acting in the direction of wave propagation $(\amalg)$ and particle motion $(\perp)$, respectively; the factor $\theta$ represents the hydrate influence in the pore space; and $\alpha$ and $\beta$ are factors calculated from tests conducted on sediment without hydrates $\left(S_{h}=0\right)$.

Under high strain conditions, it was found that (1) the undrained shear strength $\left(S_{\mathcal{u}}\right)$ at low hydrate concentration is determined by the effective stress-dependent frictional strength, (2) the contribution of the hydrate strength increases nonlinearly with higher strength, gaining relevance at high $S_{h}$, and (3) in the case of fine-grained soils, the effect of hydrate tends to be more pronounced at low porosity. The following expression for $S_{u}$ captures these observations:

$$
S_{u}=a \sigma_{o}^{\prime}+b q_{h}\left(\frac{S_{h}}{\varepsilon}\right)^{2} .
$$

Here a nominal value for the hydrate strength, $q_{h}=8 \mathrm{MPa}$, was assumed. This value is within the range reported in the literature [79]. The coefficient a represents friction and pore pressure generation in the sediment, while $\mathrm{b}$ is an indication of the hydrate's ability to contribute to the strength of the hydrate-bearing sediment.

The electrical conductivity of hydrate-bearing sediments, $\sigma_{\mathrm{hbs}}$, at radiofrequencies is determined by the volume fraction of the unfrozen pore fluid and the pore fluid 
conductivity $\left(\sigma_{w}\right)$. The resulting expression fitted their experimental data:

$$
\sigma_{\mathrm{hbs}}=\sigma_{w}\left[\varepsilon\left(1-S_{w}\right)\right]^{1.6} .
$$

The electrical permittivity $\left(\kappa_{\mathrm{hbs}}\right)$ in the microwave frequency range is determined by the polarization of the free, unfrozen water. Most of their experimental data at $S_{w}=0.5$ were fitted by

$$
\kappa_{\mathrm{hbs}}=5+70 \varepsilon\left(1-S_{h}\right) .
$$

The thermal conductivity $\left(K_{\mathrm{hbs}}\right)$ was determined using the needle probe technique in sediments subjected to isotropic confinement [32]. The experimental data showed that the thermal conductivity increases with decreasing porosity in soils without hydrates. Santamarina et al. [73] demonstrated that the general Pythagorean mixing formula is applicable, leading to

$$
K_{\mathrm{hbs}}=\left[\varepsilon\left(S_{h} K_{h}^{s}+S_{w} K_{w}^{s}\right)+(1-\varepsilon) K_{m}^{s}\right]^{1 / s} .
$$

Note that this expression can be readily extended to include ice and gas phases in cases where these phases may be present. The parallel model corresponds to $s=1$, and the series model corresponds to $s=-1$. Adequate predictions for a given soil are obtained with exponents in the $s \approx \pm 0.2$ range. The authors found that, while the thermal conductivity of hydrate is very similar to that of water, marked changes in thermal conductivity occur when high $S_{h}$ is present in soils.

Santamarina et al. [73] stated that they have emphasized the determination of data trends using physically based mathematical relationships that combine material parameters, instead of merely fitting generic mathematical functions to the data.

It was also noted that the correlation of the measured physical parameters always requires that the hydrate saturation in pore space, which ranges from 0 to 1 , be raised to a power greater than 1 . This fact significantly reduces the impact of low-hydrate saturations on the measured physical parameters, an effect that is particularly pronounced at the hydrate saturations characteristic of many natural systems $(<0.2$ of pore space). Mechanical properties are strongly influenced by both soil properties and the hydrate loci. Thermal conductivity depends on the complex interplay of a variety of factors, including formation history, and cannot be easily predicted by volume average formulations [73].

\section{Conclusions}

All three main hydrate structures (sI, sII, and sH) are approximately $85 \%(\mathrm{~mol})$ water and $15 \%$ gas when all the cages are filled. This fact suggests that the mechanical properties of the three hydrate structures are similar to those of ice. This conclusion is true to a first approximation, with the exception of thermal conductivity and thermal expansivity. Thermal conductivity of bulk hydrates slightly increases with temperature, contrary to the ice thermal conductivity that decreases with temperature raised to the power of -1 .
The physical properties of bulk hydrates are remarkably close to those of pure ice. As a result, the properties of sediments containing hydrate in the pore space are similar to sediments containing normal ice. The morphology of gas hydrates has large effects on sedimentary physical properties, from seismic velocities on a large scale to borehole electrical resistivity on a smaller scale, and, therefore, the gas hydrate morphology impacts the amount of gas hydrate saturation estimated from geophysical data. Hydrate morphology is controlled by the nature of the sediment host as much as by the supply of the necessary chemical components and environmental conditions.

The most readily observable change in sediment physical properties resulting from the formation of gas hydrates is an increase in seismic velocity. Locating likely areas of gas hydrates using remote seismic sensing is relatively straightforward where bottom-simulating reflectors (BSR) are evident. A BSR is a high-amplitude reflector that approximately parallels the seafloor and results from the strong acoustic impedance contrast between the gas-hydratebearing sediments above the reflector and the underlying sediments containing free gas. Gas hydrates may be present even where there is no BSR identified from reflection seismic records.

The understanding of the thermal properties of hydratebearing sediments is crucial for the future exploitation of methane gas trapped in sediments. In sediment-bearing hydrates, the thermal conductivity reflects the competing effects of the thermal conductivity of the phases involved, their volume fraction, and their spatial distribution. The electrical conductivity is controlled by the availability and mobility of ions. A gradual reduction in conductivity is measured during hydrate formation even though ion exclusion keeps available ions within the unfrozen water. Mechanical properties are strongly influenced by both soil properties and the hydrate loci.

All the physical parameters depend strongly on the hydrate saturation in pore space. This fact significantly reduces the impact of low-hydrate saturations on the measured physical parameters, an effect that is particularly pronounced at the hydrate saturations characteristic of many natural systems $(<0.2$ of pore space).

\section{Acknowledgments}

Funding for this work was provided by the Department of Energy, National Energy and Technology Laboratory, to Georgia Institute of Technology under Contract no. DE-FC26-06NT42963 and to Prairie View A\&M University under Contract no. DE-FG26-06NT42746. Oak Ridge National Laboratory is managed by UT-Battelle, LLC, for the US Department of Energy under contract DE-AC0500OR22725.

\section{References}

[1] P. Englezos, "Clathrate hydrates," Industrial \& Engineering Chemistry Research, vol. 32, no. 7, pp. 1251-1274, 1993.

[2] E. D. Sloan Jr., "Gas hydrates: review of physical/chemical properties," Energy \& Fuels, vol. 12, no. 2, pp. 191-196, 1998. 
[3] E. D. Sloan Jr., Clathrate Hydrates of Natural Gases, Marcel Dekker, New York, NY, USA, 3rd edition, 2006.

[4] E. G. Hammerschmidt, "Formation of gas hydrates in natural gas transmission Lines," Industrial \& Engineering Chemistry, vol. 26, no. 8, pp. 851-855, 1934.

[5] Y. F. Makogon, "Hydrate formation in gas bearing strata under perma frost," Gazov Prom-st, vol. 5, pp. 14-15, 1965.

[6] K. A. Kvenvolden and T. D. Lorenson, "The global occurrence of natural gas hydrate," in Natural Gas Hydrates, Occurrence, Distribution, and Detection. Geophysical Monograph, C. K. Paull and W. P. Dillon, Eds., vol. 124, pp. 3-18, American Geophysical Union, Washington, DC, USA, 2001.

[7] T. S. Collett, "Natural-gas hydrates; resource of the twentyfirst century?" Journal of the American Association of Petroleum Geologists, vol. 74, pp. 85-108, 2001.

[8] I. Lerche and E. Bagirov, "Guide to gas hydrate stability in various geological settings," Marine and Petroleum Geology, vol. 15, pp. 427-438, 1998.

[9] K. A. Kvenvolden, "Gas hydrates-geological perspective and global change," Reviews of Geophysics, vol. 31, no. 2, pp. 173$187,1993$.

[10] R. K. McMullan and G. A. Jeffrey, "Polyhedral clathrate hydrates. IX. Structure of ethylene oxide hydrate," The Journal of Chemical Physics, vol. 42, no. 8, pp. 2725-2732, 1965.

[11] C. W. Mak and R. K. McMullan, "Polyhedral clathrate hydrates. X. Structure of double hydrate of tetrahydrofuran and hydrogen sulfide," The Journal of Chemical Physics, vol. 42, pp. 2732-2737, 1965.

[12] C. A. Koh, "Towards a fundamental understanding of natural gas hydrates," Chemical Society Reviews, vol. 31, no. 3, pp. 157$167,2002$.

[13] J. A. Ripmeester, J. S. Tse, C. I. Ratcliffe, and B. M. Powell, "A new clathrate hydrate structure," Nature, vol. 325, no. 6100, pp. 135-136, 1987.

[14] J. A. Ripmeester, "The role of heavier hydrocarbons in hydrate formation," in Proceedings of the AIChE Spring Meeting, Houston, Tex, USA, April 1991.

[15] A. P. Mehta and E. D. Sloan Jr., "Structure H hydrate phase equilibria of methane + liquid hydrocarbon mixtures," Journal of Chemical \& Engineering Data, vol. 38, no. 4, pp. 580-582, 1993.

[16] A. P. Mehta and E. D. Sloan Jr., "Structure H hydrate phase equilibria of paraffins, naphthenes, and olefins with methane," Journal of Chemical \& Engineering Data, vol. 39, pp. 887-890, 1994.

[17] A. P. Mehta and E. D. Sloan Jr., "A thermodynamic model for structure-H hydrates," AIChE Journal, vol. 40, no. 2, pp. 312320, 1994.

[18] A. P. Mehta and E. D. Sloan Jr., "Improved thermodynamic parameters for prediction of structure $\mathrm{H}$ hydrate equilibria," AIChE Journal, vol. 42, no. 7, pp. 2036-2046, 1996.

[19] R. Sassen and I. R. MacDonald, "Evidence of structure H hydrate, Gulf of Mexico continental slope," Organic Geochemistry, vol. 22, no. 6, pp. 1029-1032, 1994.

[20] K. A. Udachin, C. I. Ratcliffe, and J. A. Ripmeester, "A dense and efficient clathrate hydrate structure with unusual cages," Angewandte Chemie, vol. 40, no. 7, pp. 1303-1305, 2001.

[21] J. S. Loveday, R. J. Nelmes, M. Guthrie, et al., "Stable methane hydrate above $2 \mathrm{GPa}$ and the source of Titan's atmospheric methane," Nature, vol. 410, no. 6829, pp. 661-663, 2001.

[22] I.-M. Chou, A. Sharma, R. C. Burruss, et al., "Transformations in methane hydrates," Proceedings of the National Academy of Sciences of the United States of America, vol. 97, no. 25, pp. 13484-13487, 2000.
[23] L. Yang, C. A. Tulk, D. D. Klug, et al., "Synthesis and characterization of a new structure of gas hydrate," Proceedings of the National Academy of Sciences of the United States of America, vol. 106, no. 15, pp. 6060-6064, 2009.

[24] D. W. Davidson, "Gas hydrates as clathrates of ices," in Natural Gas Hydrates: Properties, Occurrence and Recovery, J. L. Cox, Ed., pp. 1-16, Butterworths, Boston, Mass, USA, 1983.

[25] J. S. Tse, "Dynamicl properties and stability of clathrate hydrates," Annals of the New York Academy of Sciences, vol. 715, pp. 187-206, 1994, 1st International Conference on Natural Gas Hydrates.

[26] J. G. Cook and D. G. Leaist, "An exploratory study of the thermal conductivity of methane hydrate," Geophysical Research Letters, vol. 10, no. 5, pp. 397-399, 1983.

[27] R. G. Ross, P. Anderson, and G. Backstrom, "Effects of H and D order on the thermal conductivity of ice phases," The Journal Chemistry Physics, vol. 68, no. 9, pp. 3967-3972, 1978.

[28] R. D. Stoll and G. M. Bryan, "Physical properties of sediments containing gas hydrates," Journal of Geophysical Research, vol. 84, no. B4, pp. 1629-1634, 1979.

[29] T. Ashworth, L. R. Johnson, and L. P. Lai, "Thermal conductivity of pure ice and tetrahydrofuran clathrate hydrates," High Temperatures-High Pressures, vol. 17, no. 4, pp. 413-419, 1985.

[30] J. S. Tse and M. A. White, "Origin of glassy crystalline behavior in the thermal properties of clathrate hydrates: a thermal conductivity study of tetrahydrofuran hydrate," The Journal of Physical Chemistry, vol. 92, no. 17, pp. 5006-5011, 1988.

[31] O. Andersson and H. Suga, "Thermal conductivity of normal and deuterated tetrahydrofuran clathrate hydrates," Journal of Physics and Chemistry of Solids, vol. 57, no. 1, pp. 125-132, 1996.

[32] A. I. Martin, Hydrate bearing sediments - thermal conductivity, M.S. thesis, School of Civil and Environmental Engineering, Georgia Institute of Technology, Atlanta, Ga, USA, 2004.

[33] D. Klaeschen, M. Zillmer, and J. Bialas, "IFM-GEOMAR Report 2002-2004," chapter 3, http://www.ifm-geomar.de/ index.php?id=3500.

[34] R. A. Duncan, H.C. Larsen, J. F. Allan, et al., "Proceedings of the Ocean Drilling Program," Initial Report 164, Ocean Drilling Program, College Station, Tex, USA, 1996.

[35] N. Lubick, “Detecting marine gas hydrates," Geotimes, vol. 49, no. 11, pp. 28-30, 2004.

[36] T. Yuan, K. S. Nahar, R. Chand, R. D. Hyndman, G. D. Spence, and N. R. Chapman, "Marine gas hydrates: seismic observations of bottom-simulating reflectors off the west coast of Canada and the east coast of India," Geohorizons, vol. 3, no. 1, pp. 1-11, 1998.

[37] S. Constable, "Marine electromagnetic methods for gas hydrate characterization," submitted to Seafloor Electromagnetic Methods Consortium, http://marineemlab.ucsd.edu/ Projects/GoMHydrate/Proposal_3.pdf.

[38] M. Holland, P. Schultheiss, J. Roberts, and M. Druce, "Observed gas hydrate morphologies in marine sediments," in Proceedings of the 6th International Conference on Gas Hydrates (ICGH '08), Vancouver, Canada, July 2008.

[39] R. Malone, "Gas hydrates topical report," Tech. Rep. DOE/METC/SP-218 (DE85001986), Department of Energy, Morgantown Energy Technology Center, Morgantown, WVa, USA, 1985.

[40] A. E. Cook and D. Goldberg, "Gas hydrate filled fracture distribution, eastern Indian continental margin," in Proceedings of the American Geophysical Union. Fall Meeting, San Francisco, Calif, USA, 2007, abstract no. OS11C-04. 
[41] D. Long, M. A. Lovell, J. G. Rees, and C. A. Rochelle, "Sediment-hosted gas hydrates: new insights on natural and synthetic systems," Geological Society of London, vol. 319, pp. $1-9,2009$.

[42] M. B. Clennell, M. Hovland, J. S. Booth, P. Henry, and W. J. Winters, "Formation of natural gas hydrates in marine sediments-part 1: conceptual model of gas hydrate growth conditioned by host sediment properties," Journal of Geophysical Research B, vol. 104, no. B10, pp. 22985-23003, 1999.

[43] P. Henry, M. Thomas, and M. B. Clennell, "Formation of natural gas hydrates in marine sediments-part 2: thermodynamic calculations of stability conditions in porous sediments," Journal of Geophysical Research B, vol. 104, no. B10, pp. 2300523022, 1999.

[44] R. L. Kleinberg, C. Flaum, D. D. Griffin, et al., "Deep sea NMR: methane hydrate growth habit in porous media and its relationship to hydraulic permeability, deposit accumulation, and submarine slope stability," Journal of Geophysical Research, vol. 108, p. 2508, 2003.

[45] A. P. Camps, Hydrate formation in near surface ocean sediments, unpublished thesis, Department of Geology, University of Leicester, Leicester, UK, 2007.

[46] M. Riedel, T. S. Collet, M. J. Malone, and Expedition 311 Scientists, "Expedition 311 summary," in Proceedings of the Integrated Ocean Drilling Program (IODP '06), vol. 311, Integrated Ocean Drilling Program Management International, Washington, DC, USA, 2006.

[47] R. Anderson, M. Llamedo, B. Tohidi, and R. W. Burgass, "Experimental measurement of methane and carbon dioxide clathrate hydrate equilibria in mesoporous silica," The Journal of Physical Chemistry B, vol. 107, no. 15, pp. 3507-3514, 2003.

[48] M. Llamedo, R. Anderson, and B. Tohidi, "Thermodynamic prediction of clathrate hydrate dissociation conditions in mesoporous media," American Mineralogist, vol. 89, no. 8-9, pp. 1264-1270, 2004.

[49] U. Tinivella, F. Accaino, M. Giustiniani, and M. F. Loreto, "Gas hydrate and mud volcanoes offshore Antarctic Peninsula: a geophysical study," in Proceedings of the Goldschmidt Conference, Davos, Switzerland, June 2009.

[50] C. Ecker, J. Dvorkin, and A. M. Nur, "Estimating the amount of gas hydrate and free gas from marine seismic data," Geophysics, vol. 65, no. 2, pp. 565-573, 2000.

[51] J. Dvorkin, M. Helgerud, W. Waite, S. Kirby, and A. Nur, "Introduction to physical properties and elasticity models," in Natural Gas Hydrate in Oceanic and Permafrost Environments, M. D. Max, Ed., pp. 245-260, Kluwer Academic Publishers, Dordrecht, The Netherlands, 2000.

[52] G. E. Archie, "The electrical resistivity log as an aid in determining some reservoir characteristics," Petroleum Transactions of AIME, vol. 146, pp. 54-62, 1942.

[53] E. Spangenberg, "Modeling of the influence of gas hydrate content on the electrical properties of porous sediments," Journal of Applied Geophysics, vol. 56, no. 1, pp. 73-78, 2004.

[54] B. Tohidi, R. Anderson, M. B. Clennell, R. W. Burgass, and A. B. Biderkab, "Visual observation of gas-hydrate formation and dissociation in synthetic porous media by means of glass micromodels," Geology, vol. 29, no. 9, pp. 867-870, 2001.

[55] E. Kingston, Ch. Clayton, and J. Priest, "Gas hydrate growth morphologies and their effect on the stiffness and damping of a hydrate bearing sand," in Proceedings of the 6th International Conference on Gas Hydrates (ICGH '08), Vancouver, Canada, July 2008.
[56] G. J. Moridis, T. S. Collett, S. R. Dallimore, T. Satoh, S. Hancock, and B. Weatherill, "Numerical studies of gas production from several $\mathrm{CH}_{4}$ hydrate zones at the Mallik site, Mackenzie Delta, Canada," Journal of Petroleum Science and Engineering, vol. 43, no. 3-4, pp. 219-238, 2004.

[57] A. Koponen, M. Kataja, and J. Timonen, "Permeability and effective porosity of porous media," Physical Review E, vol. 56, no. 3, pp. 3319-3325, 1997.

[58] M. Singh and K. K. Mohanty, "Permeability of spatially correlated porous media," Chemical Engineering Science, vol. 55, no. 22, pp. 5393-5403, 2000.

[59] Y. Bernabè, U. Mok, and B. Evans, "Permeability-porosity relationships in rocks subjected to various evolution processes," Pure and Applied Geophysics, vol. 160, no. 5-6, pp. 937-960, 2003.

[60] C. H. Arns, M. A. Knackstedt, and N. S. Martys, "Crossproperty correlations and permeability estimation in sandstone," Physical Review E, vol. 72, no. 4, Article ID 046304, pp. $1-12,2005$.

[61] S. Jin, J. Nagao, S. Takeya, et al., "Structural investigation of methane hydrate sediments by microfocus X-ray computed tomography technique under high-pressure conditions," Japanese Journal of Applied Physics, vol. 45, no. 27, pp. L714-L716, 2006.

[62] Y. Jin, J. Nagao, J. Hayashi, et al., "Assessment of the absolute permeability of natural methane hydrate sediments by microfocus X-ray computed tomography," in Proceedings of the 7th ISOPE Ocean Mining Symposium, pp. 93-96, Lisbon, Portugal, July 2007.

[63] H. Minagawa, Y. Nishikawa, I. Ikeda, et al., "Relation between permeability and pore-size distribution of methane-hydratebearing sediments," in Proceedings of the Offshore Technology Conference, Houston, Tex, USA, May 2008.

[64] Y. Yang and A. C. Aplin, "Influence of lithology and compaction on the pore size distribution and modeled permeability of some mudstones from the Norwegian margin," Marine and Petroleum Geology, vol. 15, no. 2, pp. 163-175, 1998.

[65] I. N. Tsimpanogiannis and P. C. Lichtner, "Parametric study of methane hydrate dissociation in oceanic sediments driven by thermal stimulation," Journal of Petroleum Science and Engineering, vol. 56, no. 1-3, pp. 165-175, 2007.

[66] J. Dvorkin and A. Nur, "Seismic amplitudes from gas hydrates," E\&P, November 2007.

[67] A. Judge, "Natural gas hydrate in Canada," in Proceedings of the 4th Canadian Permafrost Conference, pp. 320-328, 1982.

[68] R. D. Stoll, J. Edwing, and G. M. Bryan, "Anomalous wave velocities in sediments containing gas hydrates," Journal of Geophysical Research, vol. 76, no. 8, pp. 2090-2094, 1971.

[69] R.D. Stoll, "Effects of gas hydrates in sediments," in Natural Gases in Marine Sediments, L. R. Kaplan, Ed., pp. 235-247, Plenum Press, New York, NY, USA, 1974.

[70] C. Pearson, J. Murphy, and R. Hermes, "Acoustic and resistivity measurements on rock samples containing tetrahydrofuran hydrates: laboratory analogues to natural gas hydrate deposits," Journal of Geophysical Research, vol. 91, no. 14, pp. 14132-14138, 1986.

[71] C. Pearson, P. M. Halleck, P. L. McGuire, R. Hermes, and M. Mathews, "Natural gas hydrate deposits: a review of in situ properties," The Journal of Physical Chemistry, vol. 87, no. 21, pp. 4180-4185, 1983.

[72] W. F. Murphy, "Acoustic measures of partial gas saturation in tight sandstones," Journal of Geophysical Research, vol. 89, no. 13, pp. 11549-11559, 1984. 
[73] J. C. Santamarina and C. Ruppel, "The impact of hydrate saturation on the mechanical, electrical, and thermal properties of hydrate-bearing sand, silts, and clay," in Proceedings of the 6th International Conference on Gas Hydrates (ICGH '08), Vancouver, Canada, July 2008.

[74] J. C. Santamarina, F. Francisca, T. S. Yun, J. Y. Lee, A. I. Martin, and C. Ruppel, "Mechanical, thermal, and electrical properties of hydrate bearing sediments," in Proceedings of the AAPG Hedberg Research Conference, Vancouver, Canada, September 2004.

[75] W. J. Winters, W. F. Waite, D. H. Mason, L. Y. Gilbert, and I. A. Pecher, "Methane gas hydrate effect on sediment acoustic and strength properties," Journal of Petroleum Science and Engineering, vol. 56, no. 1-3, pp. 127-135, 2007.

[76] A. Fernandez and J. C. Santamarina, "The effect of cementation on the small strain parameters of sands," Canadian Geotechnical Journal, vol. 38, no. 1, pp. 191-199, 2001.

[77] T. S. Yun, J. C. Santamarina, and C. Ruppel, "Mechanical properties of sand, silt, and clay containing tetrahydrofuran hydrate," Journal of Geophysical Research, vol. 112, Article ID B04106, 2007.

[78] J. C. Santamarina, K. A. Klein, and M. A. Fam, Soils and Waves: Particulate Materials Behavior, Characterization and Process Monitoring, vol. 488, John Wiley \& Sons, New York, NY, USA, 2001.

[79] W. B. Durham, L. A. Stern, S. H. Kirby, and S. Circone, "Rheological comparisons and structural imaging of sI and sII end member gas hydrates and hydrate/sediment aggregates," in Proceedings of the 5th International Conference on Gas Hydrates, Tapir Academic, Trondheim, Norway, 2005. 

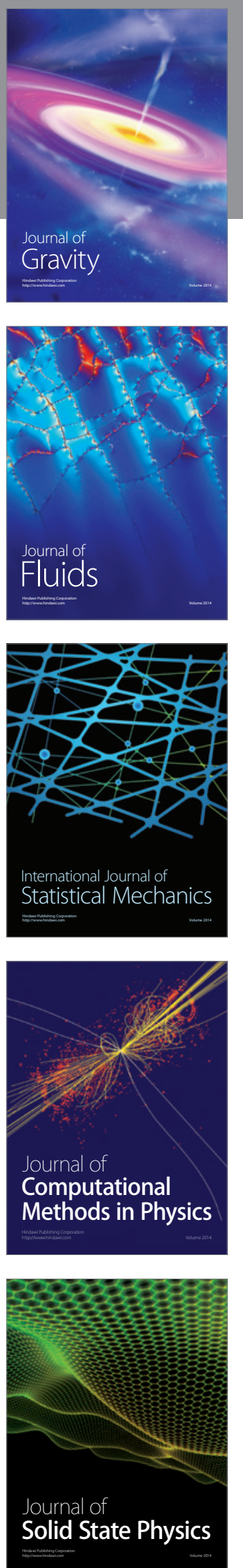

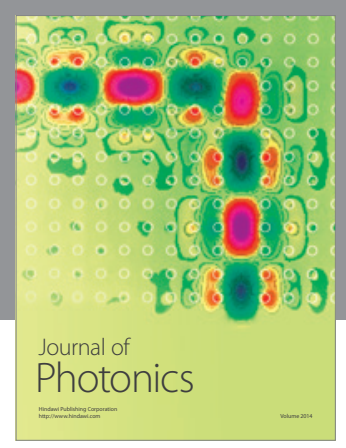

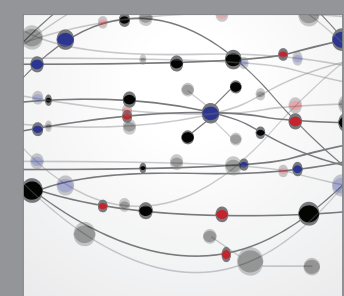

The Scientific World Journal
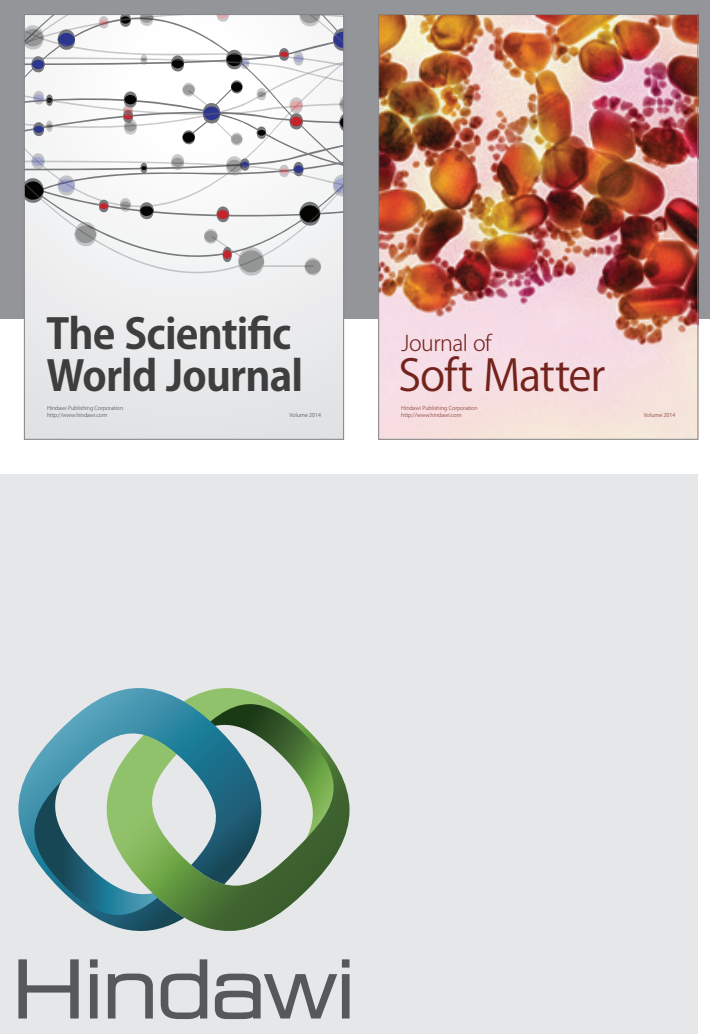

Submit your manuscripts at

http://www.hindawi.com
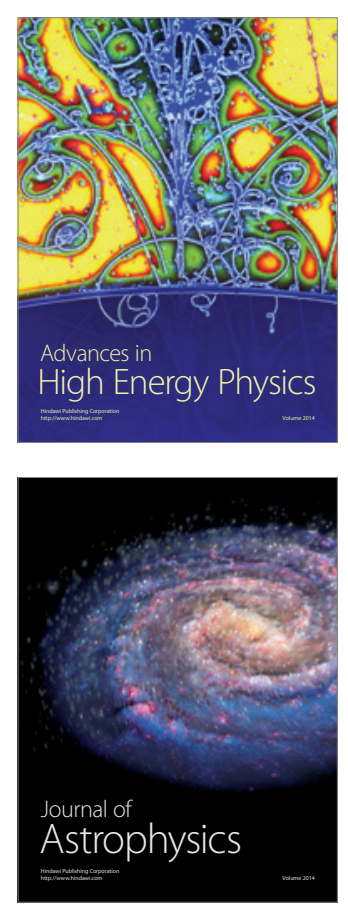
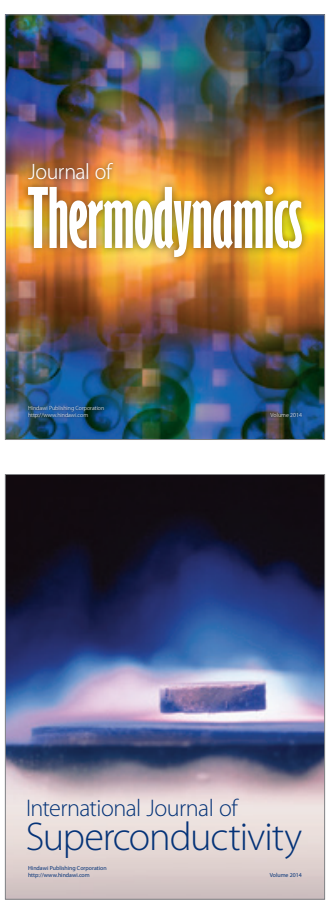
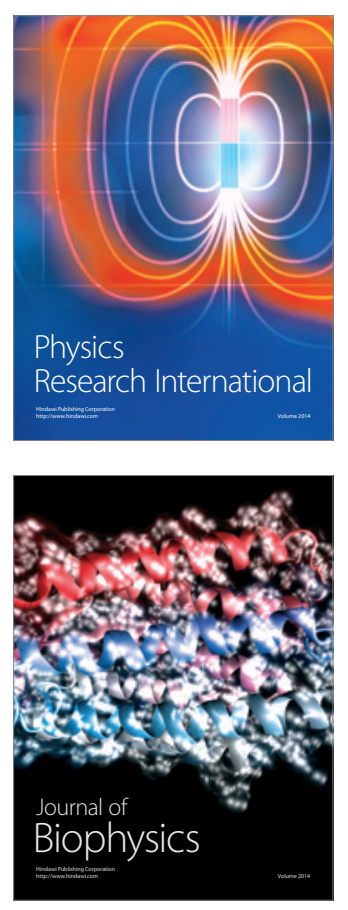
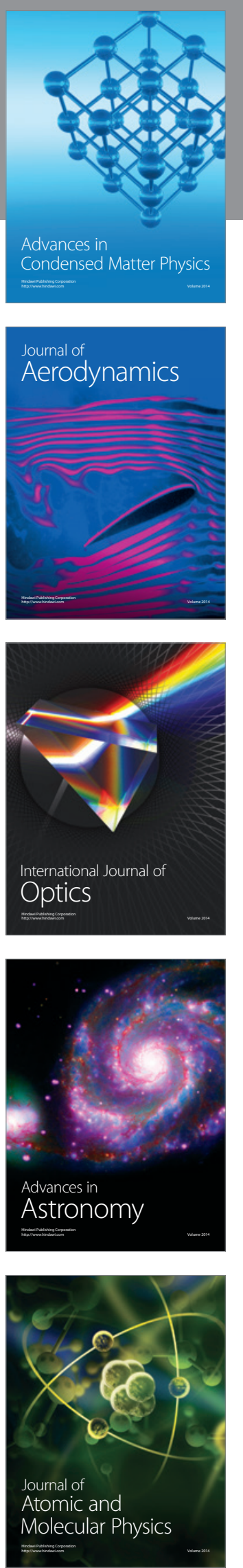